\title{
Pengaruh Model Pembelajaran Matematika Realistik Berbasis Media Terhadap Kesulitan Belajar Siswa
}

\author{
Firda Halawati
}

C 2019 JEMS (Jurnal Edukasi Matematika dan Sains)

This is an open access article under the CC-BY-SA license (https://creativecommons.org/licenses/bysa/4.0/) ISSN 2337-9049 (print), ISSN 2502-4671 (online)

\begin{abstract}
Abstrak:
Tujuan dari penelitian ini adalah untuk mengetahui apakah terdapat pengaruh model pembelajaran matematika realistik terhadap kesulitan belajar siswa. Penelitian ini menggunakan metode Pre-experimental dengan one group pretest posttest design. Populasi didalam penelitian ini adalah seluruh siswa SMP 1 Kuningan Jawa Barat yang berjumlah 960 siswa. Teknik pengambilan sampel menggunakan teknik sampling purposive. Penguasaan materi diukur dengan menggunakan tes pilihan ganda. Tes diberikan pada tes awal (pre-test) dan tes akhir (post-test). Hasil penelitian ini menunjukkan bahwa rata-rata tes awal dan tes akhir terdapat kenaikkan 30\% dan terdapat pengaruh model pembelajaran matematika realistik berbasis media terhadap kesulitan belajar siswa.
\end{abstract}

Kata Kunci : Matematika Realistik; Media; Kesulitan belajar Siswa

\begin{abstract}
:
The purpose of this study is to determine whether there is an influence of realistic mathematics learning models on student learning difficulties. This study uses a pre-experimental method with one group pre-test and post-test design. The population in this study were all students of SMP 1 Kuningan West Java, amounting to 960 students. The sampling technique uses a purposive sampling technique. Material mastery is measured using a multiple-choice test. Tests are given at the initial test (pretest) and final test (post-test). The results of this study indicate that the average of the initial test and the final test there is an increase of $30 \%$, and there is an influence of media-based realistic mathematics learning models on student learning difficulties.
\end{abstract}

Keywords : Realistic Mathematics; Media; Student Learning Difficulties

\section{Pendahuluan}

Menurut Van de Henvel Panhuizen (Suharta, 2002), bahwa “Bila anak belajar matematika terpisah dari pengalaman mereka sehari-hari maka anak akan cepat lupa dan tidak dapat mengaplikasikan matematika". Berdasarkan pendapat tersebut, pembelajaran matematika di kelas hendaknya ditekankan pada keterkaitan antara konsep-konsep matematika dengan pengalaman anak sehari-hari. Selain itu, menerapkan kembali konsep matematika yang telah dimiliki anak pada kehidupan sehari-hari atau padabidang lain sangat penting dilakukan. Menurut Johnson dan Rising (Rusefendi, 2008) bahwa "Matematika ialah pola berpikir, pembuktian yang logis, pola mengorganisasikan, matematika adalah suatu bahasa dengan menggunakan istilah yang dapat didefinisikan secara akurat, cermat, dan jelas, representasinya dengan simbol serta padat, lebih berupa sebuah bahasa simbol tentang ide dibandingkan tentang bunyi".Matematika merupakan ilmu pengetahuan yang mempelajari struktur yang abstrak dan pola hubungan yang ada didalamnya. Hal ini berarti bahwa belajar matematika pada hakekatnya 
adalah belajar konsep, struktur konsep dan mencari hubungan antar konsep dan strukturnya. Pada hakikatnya kegiatan belajar mengajar adalah suatu proses komunikasi. Dalam proses komunikasi, kehadiran media sangatlah penting agar pesan yang disampaikan oleh komunikator dapat diterima oleh komunikan secara efektif. Demikian juga dalam pembelajaran, agar tujuan pembelajaran dapat dicapai secara efektif dan efisien maka diperlukan media pembelajaran yang memudahkan siswa belajar. Apalagi pada pembelajaran matematika yang memiliki tingkat kesulitan dan keabstrakan konsep yang lebih tinggi dibanding dengan mata pelajaran yang lain. Serangkaian masalah yang meliputi dunia kependidikan dewasa ini masih perlu mendapat perhatian dari semua pihak. Mulai dari kualitas tenaga pendidik yang belum mencapai target hingga masalah kesejahteraan guru. Fakta di lapangan, permasalahan jauh lebih kompleks dalam lingkungan pendidikan kita. Boleh dikatakan tingkat kualitas dan kompetensi guru menjadi kendala utamanya, mulai dari guru yang tidak memiliki kelayakan kompetensi untuk mengajar mata pelajaran tertentu, hingga rendahnya tingkat profesionalisme guru itu sendiri. Adapun prestasi belajar matematika secara umum berdasarkan fakta di lapangan, guru kelas menjelaskan bahwa prestasi belajar pada mata pelajaran matematika pada saat ini belum mencapai hasil yang diharapkan sesuai dengan kriteria ketuntasan Minimal (KKM), secara presentase dikemukakan bahwa $40 \%$ siswa mencapai nilai KKM, dan 60\% siswa belum mencapai KKM, dengan hasil seperti itu, guru kelas mengungkapkan salahs atu alasan dan indikasinya karena pembelajaran masih mengandalkan metode klasikal.

Dalam pembelajaran matematika model yang sesuai dengan filosofi konstruktivisme dan kontekstual adalah Pendidikan Matematika Realistik (PMR). Model ini dikembangkan di Belanda, bertumpu pada filosofi Freudenthal yang menyatakan bahwa matematika adalah aktivitas manusia, dan semua unsur matematika dalam kehidupan sehari-hari harus digunakan untuk membelajarkan matematika di kelas. PMR menggabungkan pandangan tentang apa itu matematika,bagaimana siswa belajar matematika dan bagaimana matematika harus diajarkan. Siswa tidak boleh dipandang sebagai objek belajar, melainkan sebagai subjek belajar sehingga diharapkan siswa benar-benar mampu menguasai konsep. Pembelajaran matematika realistik menggunakan masalah kontekstual (contextual problem) sebagai titik tolak dalam belajar matematika. Perlu diketahui bahwa suatu hal yang bersifat kontekstual dalam lingkungan siswa di suatu daerah, belum tentu bersifat konteks bagi siswa di daerah lain. Oleh karena itu pembelajaran matematika dengan pendekatan realistik harus disesuaikan dengan keadaan tempat tinggal siswa. Selain penerapan matematika dalam masalah kehidupan sehari-hari, siswa diberi kesempatan untuk memahami konsep, notasi, model, prosedur, operasi dan pemecahan masalah matematika lainnya. Sebagai aktivitas manusia, materi matematika harus ditemukan sendiri oleh siswa. Mereka belajar membentuk model (formal atau tidak formal) berdasarkan soal yang disajikan. Pada akhirnya mereka juga akan membentuk sendiri struktur dan pemahaman dan pengetahuan formal matematika mereka. Kesempatan yang diberikan untuk mengerjakan soal matematika dari kehidupan sehari-hari dengan pengetahuan dan pemahaman mereka sendiri akan menolong siswa membentuk pemahaman baru akan konsep dan operasi matematika

Berdasarkan uraian di atas, penelitian ini bertujuan untuk mengetahui model pembelajaran matematika realistik, untuk mengetahui bagaimana kesulitan belajar siswa pada mata pelajaran matematika dengan menggunakan model Pembelajaran Matematika Realistik berbasis media, dan, untuk mengetahui apakah terdapat pengaruh model pembelajaran matematika realistik terhadap kesulitan belajar siswa 


\section{Metode}

Metode Penelitian yang digunakan dalam penelitian ini adalah metode penelitian Preexperimental dengan one group pre-test post-test design. Dalam penlitian ini, subyek penelitian terlebih dahulu diberikan tes awal (pre-test). Setelah diberikan tes awal, selanjutnya kepada siswa tersebut diberikan perlakuan, yaitu pembelajaran matematika dengan menggunakan pembelajaran Matematika Realistik untuk kelas eksperimen dan pembelajaran Matematika dengan menggunakan media gambar untuk kelas kontrol. Setelah selesai pembelajaran matematika selanjutnya seluruh siswa diberikan tes akhir (post-test).

Instrumen yang digunakan dalam penelitian ini adalah berupa tes objektif. Tes adalah alat bantu untuk mengukur prestasi hasil belajar siswa. Semakin baik hasil belajar siswa maka akan semakin kecil tingkat kesulitan belajar siswa. Dalam penelitian ini jenis tes yang digunakan adalah tes penguasaan yakni tes awal (pre-test) dan tes akhir (post-test). Adapun pengertian dari tes awal adalah tes yang diberikan sebelum siswa diberikan perlakuan. Sedangkan tes akhir adalah tes yang diberikan sesudah proses pembelajaran berlangsung. Instrumen soal yang dibuat sebelumnya telah dilakukan uji validitas, uji reliabilitas, tingkat kesukaran soal, dan daya beda soal. Teknik analisis data yang digunakan dalam penelitian ini adalah uji independent sample t-test yang sebelumnya sudah diuji normalitas dan uji homogenitasnya dan dilanjutkan dengan uji $N$ Gain.

\section{Hasil dan Pembahasan}

Hasil belajar siswa diukur dengan menggunakan instrumen berupa soal pilihan ganda. Test ini dilakukan untuk mengetahui bagaimana pengaruh media geoboard terhadap hasil belajar siswa pada mata pelajaran matematika. Soal pilihan ganda dibagi menjadi dua, yaitu pretest 20 soal dan posttest 20 soal yang telah diuji kevalidan dan reliabilitasnya. Tes dilakukan sebelum dan sesudah diberikan perlakuan kepada kelas yang dilakukan sampel penelitian. Kelas yang dijadikan sampel oleh peneliti adalah kelas VII B untuk kelas eksperimen dan kelas VIIA untuk kelas kontrol. Perlakuan yang diberikan kepada kedua kelas tersebut berbeda, untuk kelas eksperimen adalah menggunakan model Pembelajaran Matematika Realistik berbasis media yaitu media geoboard, sedangkan untuk kelas kontrol dengan media gambar. Deskripsi data hasil penelitian nilai pretest kelas kontrol dan kelas eksperimen siswa disajikan pada tabel berikut:

Tabel 1. Nilai Pretest Kelas Kontrol dan Kelas Eksperimen

\begin{tabular}{lcc}
\hline & $\begin{array}{c}\text { Pretest Kelas } \\
\text { Kontrol }\end{array}$ & $\begin{array}{c}\text { Pretest Kelas } \\
\text { Eksperimen }\end{array}$ \\
\hline Mean & 65,74 & 67,67 \\
\hline Median & 65,00 & 70,00 \\
\hline Std. Deviation & 8,451 & 8,608 \\
\hline Minimum & 50 & 50 \\
\hline Maximum & 85 & 50 \\
\hline
\end{tabular}


Dari tabel di atas dapat diketahui rata-rata nilai pretest untuk kelas kontrol dan kelas eksperimen tidak terlalu jauh berbeda. Rata-rata kelas kontrol mempunyai nilai 65,74 dan kelas eksperimen mempunyai rata-rata sebesar 67,67. Setelah diketahui nilai pretest untuk kelas kontrol dan kelas eksperimen dilakukan uji independent sample t-test sebagai berikut :

Tabel 2. Hasil Uji Independent Sample T-test Pretest

\begin{tabular}{|c|c|c|c|c|c|c|c|c|c|c|}
\hline & & \multicolumn{2}{|c|}{$\begin{array}{c}\text { Levene's Test } \\
\text { for Equality of } \\
\text { Variances } \\
\end{array}$} & \multicolumn{7}{|c|}{ t-test for Equality of Means } \\
\hline & & \multirow[t]{2}{*}{$\mathrm{F}$} & \multirow[t]{2}{*}{ Sig. } & \multirow[t]{2}{*}{$\mathrm{t}$} & \multirow[t]{2}{*}{ Df } & \multirow[t]{2}{*}{$\begin{array}{l}\text { Sig. (2- } \\
\text { tailed) }\end{array}$} & \multirow[t]{2}{*}{$\begin{array}{c}\text { Mean } \\
\text { Difference }\end{array}$} & \multirow{2}{*}{$\begin{array}{c}\text { Std. } \\
\text { Error } \\
\text { Differe } \\
\text { nce }\end{array}$} & \multicolumn{2}{|c|}{$\begin{array}{c}\text { 95\% Confidence } \\
\text { Interval of the } \\
\text { Difference }\end{array}$} \\
\hline & & & & & & & & & Lower & Upper \\
\hline Nilai & $\begin{array}{l}\text { Equal } \\
\text { variances } \\
\text { assumed }\end{array}$ & .024 & .876 & & 62 & & 1.931 & 2.121 & -2.308 & 6.170 \\
\hline Pretest & $\begin{array}{l}\text { Equal } \\
\text { variances not } \\
\text { assumed }\end{array}$ & & & & 60.953 & & 1.931 & 2.121 & -2.310 & 6.173 \\
\hline
\end{tabular}

Berdasarkan tabel di atas, diperoleh nilai t hitung untuk pretest sebesar 0.911 dan 0.911 , nilai tersebut lebih kecil dari t tabel yaitu $0.911<1.999$. Nilai signifikannya lebih besar dari 0,05 yaitu 0,366 > 0,05. Sehingga dapat disimpulkan bahwa tidak ada perbedaan nilai pretest antara kelas eksperimen maupun kelas kontrol. Dengan demikian kemampuan kelas tersebut sama. Deskripsi data hasil penelitian nilai postest untuk kelas eksperimen yang telah diberikan perlakukan menggunakan model pembelajaran matematika realistik berbasis media geoboard dan kelas kontrol yang menggunakan media dapat disajikan pada tabel berikut:

Tabel 3. Nilai Postest Kelas Kontrol dan Kelas Eksperimen

\begin{tabular}{lcc}
\hline & $\begin{array}{c}\text { Postest Kelas } \\
\text { Kontrol }\end{array}$ & $\begin{array}{c}\text { Postest Kelas } \\
\text { Eksperimen }\end{array}$ \\
\hline Mean & 84.26 & 87.83 \\
\hline Median & 85.00 & 90.00 \\
\hline Std. Deviation & 6.757 & 6.909 \\
\hline Minimum & 70 & 75 \\
\hline Maximum & 100 & 100 \\
\hline
\end{tabular}

Dari tabel di atas dapat diketahui rata-rata nilai prostest untuk kelas kontrol dan kelas eksperimen terdapat perbedaan. Rata-rata kelas kontrol mempunyai nilai 84,26 dan kelas 
eksperimen mempunyai rata-rata sebesar 87,83 . Setelah diketahui nilai postest untuk kelas kontrol dan kelas eksperimen dilakukan uji independent sample t-test sebagai berikut:

Tabel 4. Hasil Uji Independent Sample T-test Post-test

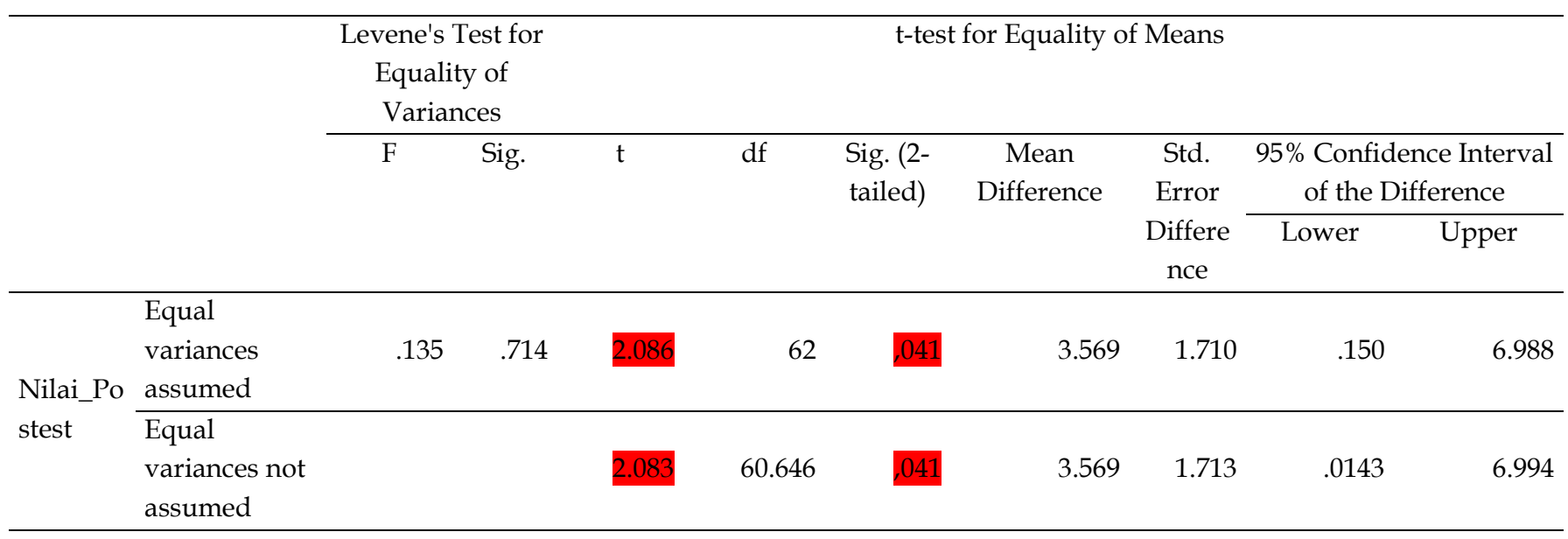

Berdasarkan tabel di atas, diperoleh nilai t hitung untuk posttest sebesar 2,086 dan 2,083, nilai tersebut lebih besar dari t tabel yaitu 2,086 > 1,999 dan 2,083 >1,999. Nilai signifikannya lebih kecil dari 0,05 yaitu 0,041<0,05.Jadi dapat disimpulkan bahwa terdapat pengaruh positif antara Pembelajaran Matematika Realistik berbasis media terhadap Kesulitan Belajar Siswa.

\section{Deskripsi Peningkatan N-Gain}

Nilai $N$-gain didapat dari selisih skor pretes dan posttest, untuk mengetahui peningkatan siswa antara kelas eksperimen dan kelas kontrol digunakan perhitungan uji $N$-gain. Berikut ini disajikan tabel deskripsi gain kelas eksperimen dan kelas kontrol:

Tabel 5. Data Gain Kelas Eksperimen dan Kontrol

\begin{tabular}{crrrc}
\hline Kelas & Pretest & Posttest & N-gain & Kriteria \\
\hline Eksperimen & 67.67 & 87.83 & 0.62 & Sedang \\
\hline Kontrol & 65.74 & 84.26 & 0.54 & Sedang \\
\hline
\end{tabular}

Berdasarkan nilai pretest dan posttest pada kedua kelas tersebut, kelas eksperimen memperoleh N-Gain sebesar 0.62 dan kelas kontrol memperoleh N-Gain sebesar 0.54. Setelah diinterpretasikan diperoleh $\mathrm{N}$-Gain kelas eksperimen sebesar 0.62 tergolong sedang, dan kelas kontrol nilai N-Gain sebesar 0.54 tergolong sedang. 
Firda Halawati

\section{Simpulan}

Pengaruh Model Pembelajaran Realistik berbasis media berlangsung baik. Pada pembelajaran dengan menggunakan Model Pembelajaran Realistik berbasis media siswa terlihat lebih aktif dan antusias dalam mengikuti proses pembelajaran. Proses belajar mengajar berlangsung lebih aktif dan menyenangkan karena siswa dapat langsung membuat bangun segi banyak pada geoboard dan mampu menghitung luas segi banyak dalam bentuk permainan dengan mudah. Hal ini memperlihatkan bahwa model Pembelajaran Matematika Realistik berbasis media dapat menjadi pemicu semangat siswa dalam belajar sehingga dapat mengatasi kesulitan belajar khususnya pada mata pelajaran matematika.

Hasil belajar siswa di kelas eksperimen dengan menggunakan model Pembelajaran matematika Realistik berbasis media pada mencapai nilai rata-rata 87,83, sedangkan hasil belajar siswa di kelas kontrol dengan menggunakan media gambar mencapai nilai rata-rata 84,26. Hal ini menunjukkan perolehan nilai dari kelas eksperimen yang menggunakan model Pembelajaran Matematika Realistik berbasis media, yaitu Geoboard lebih besar dibandingkan dengan kelas kontrol yang menggunakan media gambar.

Terdapat pengaruh baik pada mata pelajaran Matematika dengan menggunakan model PMR berbasis media geoboard untuk kelas eksperimen dan menggunakan media gambar untuk kelas kontrol. Hal ini dapat dilihat dari hasil data nilai yang diperoleh peneliti pada kelas eksperimen yang memperoleh nilai pretest sebesar 67,67 dan nilai posttest sebesar 87,83 yang mengalami peningkatan sebesar $30 \%$. Kemudian dapat dilihat dari hasil pengujian hipotesis yang memperoleh nilai thitung lebih besar dari ttabel yaitu 2,086 > 1,999 dan nilai signifikannya di bawah 0,05 yaitu 0,041<0,05 untuk kelas eksperimen. Sedangkan untuk kelas kontrol perolehan nilai thitung yaitu 2,083 > 1,999 dan perolehan nilai signifikansinya yaitu 0,041<0,05. Hal ini menunjukkan adanya peningkatan hasil belajar siswa dan mengatasi kesulitan belajar siswa, baik di kelas eksperimen maupun di kelas kontrol. Berdasarkan uji N-Gain, diperoleh N-Gain di kelas eksperimen sebesar 0,62 yang berkriteria sedang dan kelas kontrol sebesar 0,54 yang berkriteria sedang. Berdasarkan N-Gain tersebut peningkatan hasil belajar di kelas yang menggunakan Model PMR berbasis media, yaitu geoboard lebih tinggi dibandingkan dengan kelas yang menggunakan media gambar. Dengan demikian dapat disimpulkan bahwa Model PMR berbasis media, yaitu geoboard lebih efektif mengatasi kesulitan belajar siswa dalam mata pelajaran matematika dibandingkan dengan media gambar

\section{Daftar Rujukan}

Aisyah. (2007). Pengembangan Pembelajaran Matematika SD. Jakarta : Direktorat Jendral Pendidikan Tinggi Departemen Pendidikan Nasional.

Aridi, Wijaya. (2012). Pendidikan Matematika Realistik. Suatu Alternatif Pendekatan Pembelajaran Matematika. Yogyakarta : Graha Ilmu.

Faujan, Ahmad. (2002). Applying Realistic Mathematics Education. Disertasi: University Of Twente.

Freudental. (1973). Mathematics as an educational Task. Dordrecht : D. Reidel Publishing Co. 
Gerlach dan Ely. (2007). Teaching and Media. A Systematic Approach. Englewood Cliffs : PrenticeHall, Inc.

Ruseffendi. (2008). Pengajaran Matematika Modern dan Masa Kini untuk guru dan SPG. Bandung: Tarsito.

Schram. (2011). Big Medi, Little, Tools and Technologies for instruction. London : Sage Publications.

Suharta. (2002). Keefektifan Pembelajaran Matematika Pada Siswa Sekolah Dasar. Proceeding National Science Seminar malang: Universitas Negeri Malang. 